Derleme Makalesi - Review Article

\title{
Dikey Eksenli Rüzgâr Türbinleri-Küçük Ölçekli Uygulamalar
}

\author{
Sema KELEŞ ÇETİN ${ }^{1 *}$, Mustafa Serdar GENÇ², Ferhat DALDABAN ${ }^{3}$ \\ Geliş / Received: 06/11/2019 \\ Revize / Revised: 10/12/2019 \\ Kabul / Accepted: 11/12/2019
}

öz

Günümüzde rüzgar enerjisinden daha fazla faydalanabilmek için, düşey eksenli türbinlerin yaygınlaşması gerekmekte ve kırsal veya şehiriçi her türlü alanda kullanılması gerekmektedir. Dikey eksenli türbin uygulamaları için Savonius ve Darrieus tipi türbinler yoğun bir şekilde kullanılmakta olup, performanslarını arttırmak için Savonius-Darrieus rüzgar türbinleri birlikte kullanım örnekleri görülmektedir. Bu sebeple yapılan çalışmalara göre tek başına kullanılan Savonius veya Darrieus rüzgar türbinlerine kıyasla birlikte kullanımının daha etkili performans sonucunu verdiği araştırmalarda görülmüştür. Dikey eksenli türbinlerin şehiriçi uygulamaları için uygulanabilirliği düşünüldüğünde bu türbinler üzerine daha fazla çalışma yapılması gerekmekte olup ayrıca yeni tasarım araştırma ve geliştirme çalışmaları yapılmalıdır.

\section{Anahtar Kelimeler-Savonius, Darrieus, H-Darrieus Rüzgar Türbini}

\footnotetext{
${ }^{1 * S o r u m l u}$ yazar iletişim: skelescetin@gmail.com (https://orcid.org/0000-0003-4704-0176)

Fen Bilimleri Enstitüsü,Elektrik-Elektronik Mühendisliği, Erciyes Üniversitesi KAYSERI

2Iletişim: musgenc@erciyes.edu.tr (https://orcid.org/0000-0002-6540-620X)

Fen Bilimleri Enstitüsü,Enerji Mühendisliği, Erciyes Üniversitesi KAYSERI

3 İletişim: daldaban@erciyes.edu.tr (https://orcid.org/0000-0002-8157-2152)

Fen Bilimleri Enstitüsü,Elektrik-Elektronik Mühendisliği, Erciyes Üniversitesi KAYSERİ
} 


\title{
Vertical Axes Wind Turbines-Small Scale Applications
}

\begin{abstract}
Nowadays, in order to make more use of wind energy, vertical axis turbines need to become widespread and need to be used in all kinds of rural or urban areas. Savonius and Darrieus turbines are used extensively for vertical axis turbine applications and Savonius-Darrieus wind turbines are used together to improve their performance. For this reason, studies have shown that the combined use of Savonius or Darrieus wind turbines instead of alone use results in more effective performance. Considering the applicability of vertical axis turbines for urban applications, further studies are required on these turbines and new design research and development studies should be carried out.
\end{abstract}

Keywords- Savonius, Darrieus, H-Darrieus Wind Turbine 


\begin{tabular}{|c|c|c|}
\hline & $\begin{array}{l}\text { BŞEÜ Fen Bilimleri Dergisi } \\
6(2), 539-551,2019\end{array}$ & $\begin{array}{r}\text { BSEU Journal of Science } \\
\text { DOI: } 10.35193 / \text { bseufbd.643828 }\end{array}$ \\
\hline $\begin{array}{l}\text { BILECIKSEYHEDEBAL } \\
\text { ONIVERSITESI }\end{array}$ & & e-ISSN: 2458-7575 (http://dergipark.gov.tr/bseufbd) \\
\hline
\end{tabular}

\section{I.GİRIŞ}

2019 y1lı temmuz ayı itibari ile Türkiye'de toplam kurulu rüzgar gücü $7.615 \mathrm{MWm}$ olup işletmedeki rüzgar elektrik santral sayısı 183 olmakla birlikte bölgelere göre dağılımı Şekil.1'de verilmektedir [1]. Bu santrallerde kurulu türbin sayısı 3.155 tanedir. Bunun yanı sıra inşa halindeki rüzgar elektrik santral sayısı ise 17 'dir. Hali hazırda bulunan kurulu rüzgar enerji santrallerinden üretilen elektrik, toplam elektrik ihtiyacımızın \%7,40’ını karşılamaktadır [1].

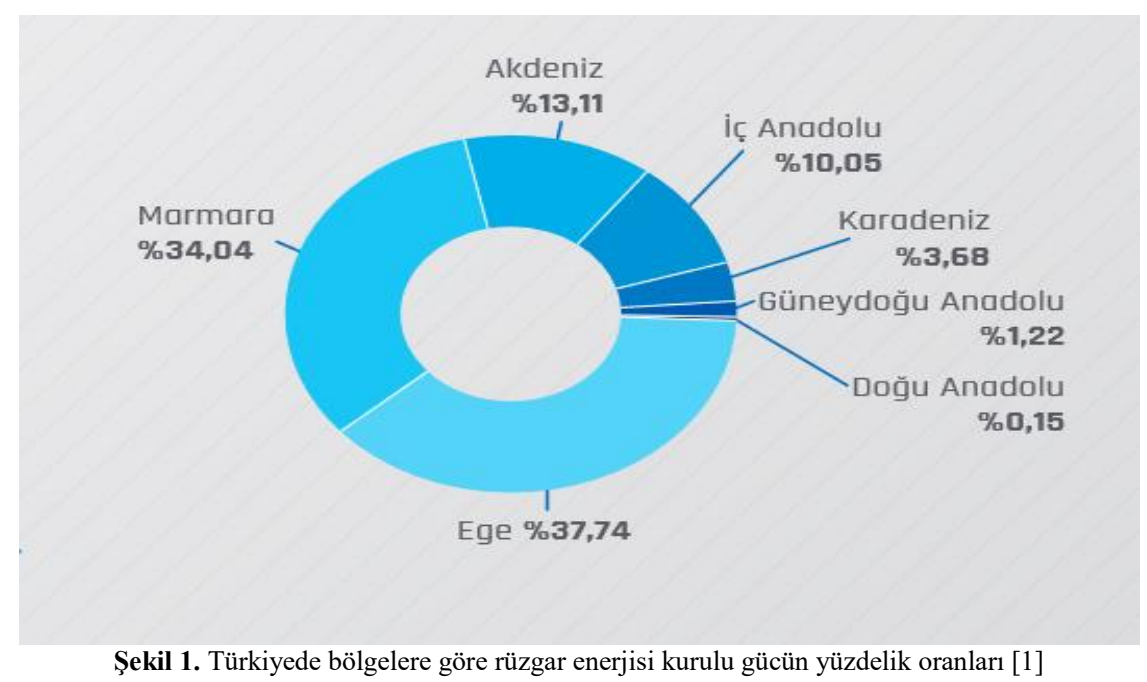

2008 yılı itibariyle rüzgar enerji santrallerinde ki kurulum miktarındaki artış Şekil 2'de verilmektedir. 2008 yılında 364 MWm üretirken 2019 yllında 7.615 MWm üretmekte olduğumuz görülmektedir [1]. Fakat Tablo 1'den görüldügü üzere Türkiye toplam rüzgar enerjisinden gelen enerji kapasitesinin yaklaşık olarak $\% 16$ 'sını kullanmaktadır [2]. Bu sebeple Türkiye'nin rüzgar enerjisinden faydalanma konusunda henüz yolun başında olduğu görülmektedir.

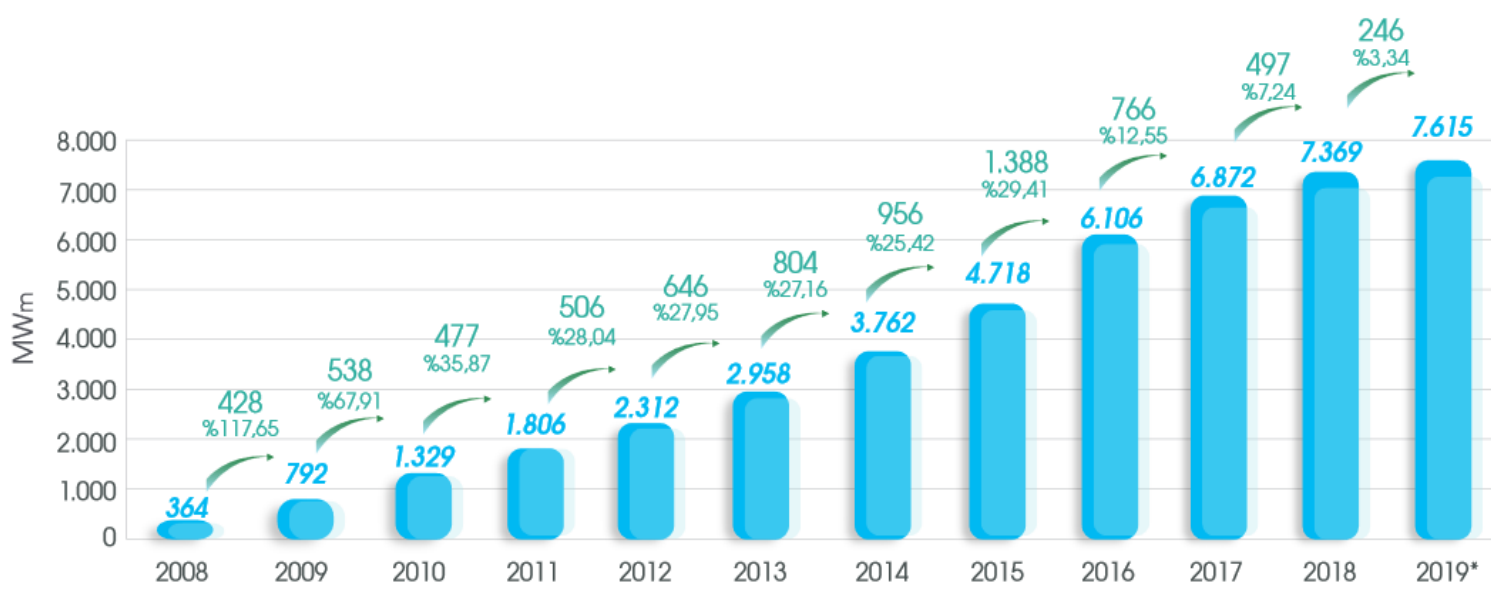

Şekil 2. Yıllara göre kurulu güç artışı [1]

Ekonomik rüzgar enerji santrali yatırımı için minimum rüzgar hızı $7 \mathrm{~m} / \mathrm{s}$ ve minumum $\% 35$ kapasite faktörü gerekmektedir [2]. Tablo.1'de görüldüğü gibi Türkiye' de rüzgar enerji potansiyeli yapılan hesaplamalar 


\begin{tabular}{|c|c|c|}
\hline & $\begin{array}{l}\text { BŞEÜ Fen Bilimleri Dergisi } \\
6(2), 539-551,2019\end{array}$ & $\begin{array}{r}\text { BSEU Journal of Science } \\
\text { DOI: } 10.35193 / \text { bseufbd.643828 }\end{array}$ \\
\hline $\begin{array}{l}\text { BIIECIISEYYEDEBALI } \\
\text { ONIVERSITESI }\end{array}$ & & e-ISSN: 2458-7575 (http://dergipark.gov.tr/bseufbd) \\
\hline
\end{tabular}

sonucunda oldukça yüksek olup ileride rüzgar enerji santral kurulumunun daha çok artacağ1 ve enerji ihtiyacımızı daha fazla karşılayabileceği öngörülmektedir [2].

Tablo 1. Türkiye'nin Rüzgar Enerji Potansiyeli [2]

\begin{tabular}{ccc}
$\begin{array}{c}\text { Y1llık ortalama Rüzgar Hızı }-\mathbf{5 0 ~ m} \\
(\mathrm{m} / \mathrm{s})\end{array}$ & $\begin{array}{c}\text { Güç Yoğunluğu }-\mathbf{5 0 ~ m} \\
\left(\mathrm{W} / \mathrm{m}^{2}\right)\end{array}$ & $\begin{array}{c}\text { Kapasite } \\
(\mathrm{MW})\end{array}$ \\
$\mathbf{7 . 0}-\mathbf{7 . 5}$ & $400-500$ & $29.259,36$ \\
$\mathbf{7 . 5}-\mathbf{8 . 0}$ & $500-600$ & $12.994,32$ \\
$\mathbf{8 . 0} \mathbf{9 . 0}$ & $600-800$ & $5.399,92$ \\
$\mathbf{9 9 . 0}$ & $>800$ & 195,84 \\
& Toplam & 47.849 \\
\hline
\end{tabular}

Dünyada rüzgar enerjisi ile elektrik üretimi yapan ülkelere bakıldığında Çin, Amerika Birleşik Devletleri ve Almanya 'nın uzun zamandır ilk üç sırada yerlerini korumaktadırlar. Rüzgar enerjisinden elektrik enerjisi üreten 100 'den fazla ülke vardır. Tablo.2'de gösterildiği gibi Türkiye, rüzgar enerji santrali kurulumunda Dünyada 11'inci sırada bulunmaktadır [4].

Tablo 2. Dünya ülkeleri içinde Türkiye'nin sıralaması [3]

\begin{tabular}{|c|c|c|c|}
\hline \multicolumn{4}{|c|}{ ÜLKELERE GÖRE DÜNYADA RÜZGAR SANTRALİ KURULU GÜCÜ LISTESİ } \\
\hline S. & ÜLKE & GÜNCELLEME & KURULU GÜÇ (MW) \\
\hline 1 & Çin & Aralık 2017 & 187.730 \\
\hline 2 & Amerika Birleşik Devletleri & Aralık 2017 & 88.927 \\
\hline 3 & Almanya & Kasim 2018 & 59.240 \\
\hline 4 & Hindistan & Aralık 2017 & 32.879 \\
\hline 5 & İspanya & Aralık 2017 & 23.026 \\
\hline 6 & Birleşik Krallık & Aralık 2017 & 17.852 \\
\hline 7 & Fransa & Aralık 2017 & 13.760 \\
\hline 8 & Brezilya & Aralık 2017 & 12.763 \\
\hline 9 & Kanada & Aralık 2017 & 12.239 \\
\hline 10 & İtalya & Aralık 2017 & 9.700 \\
\hline 11 & Türkiye & Ocak 2019 & 7.010 \\
\hline
\end{tabular}

Günümüzde dünyada rüzgardan elektrik üretimi konusunda yapılan uygulamalara baktığımızda ticari olarak kullanılan türbinlerin büyük bir kısmı yatay eksenli rüzgar türbinleridir. Rüzgar hızı yerden yükseldikçe arttığından ve daha kararlı hale geldiğinden dolayı bu türbinlerin verimleri dikey eksenli türbinlerin verimlerinden yüksektir. Fakat yerden yüksek olması bakım onarım konusunda zorluk yaşatmaktadır. Aynı zamanda yükseklik acil durumlarda müdahaleyi zorlaştırmaktadır. Bununla birlikte, rüzgar elektrik santrallerinin alan ihtiyacı gibi zorlukları da bünyesinde bulundurmaktadır.

$\mathrm{Bu}$ bahsedilen zorluklar yanında, temiz ve yenilenebilir enerji kaynağı olan rüzgar enerjisinden daha fazla faydalanmak ve artan enerji ihtiyacı ile birlikte rüzgardan gelen enerjiyi daha fazla kullanabilmek için geniş arazilerde rüzgar santralleri şeklinde uygulamalar yanında şehir içinde de rüzgar türbini uygulamaları olmalıdır. Bunun için kurulabilecek dikey eksenli ve küçük ölçekli rüzgar türbinlerinin yaygınlaşması rüzgardan daha fazla faydalanılmasını sağlayacaktır. Tablo 3'de büyük RT (rüzgar türbini) yatay eksenli rüzgar türbinlerini, küçük RT ise dikey eksenli rüzgar türbinlerini ifade etmektedir. Bu tablodan görüldügü gibi yatay eksenli türbinlerin gücü $50 \mathrm{~kW}-2 \mathrm{MW}$ arasında değişirken, dikey eksenli rüzgar türbinlerinin gücü $50 \mathrm{~W}-20 \mathrm{~kW}$ arasında değişebilmektedir. Türbin gücü olarak yatay eksenli rüzgar türbinlerinin gücü dikey eksenli rüzgar türbinlerinin gücünden oldukça fazla olabilmektedir. Fakat dikey eksenli rüzgar türbinlerinin bakım masrafının olmaması ve bunun yanı sıra kurulum masrafının düşük olması gibi avantajlarından dolayı şehir içi uygulamalarda kullanılabilmesi öngörülmelidir [4]. 
Tablo 3. Rüzgar Türbinlerinin Çeşitleri ve Birbirleriyle Karşılaştırılması [4]

\begin{tabular}{|l|c|c|c|c|c|c|}
\hline & $\begin{array}{c}\text { Kullanım } \\
\text { alanı }\end{array}$ & $\begin{array}{c}\text { Bir Tek } \\
\text { Türbin Gücü }\end{array}$ & $\begin{array}{c}\text { Üretilen Enerjinin } \\
\text { Verildiği Yer }\end{array}$ & $\begin{array}{c}\text { Akü } \\
\text { Ihtiyacı }\end{array}$ & $\begin{array}{c}\text { Bakım } \\
\text { Masrafi }\end{array}$ & $\begin{array}{c}\text { Kurulum } \\
\text { Masrafi }\end{array}$ \\
\hline Büyük RT'ler & Endüstriyel & 50kW-2MW & Şebeke & Yok & Var & Yüksek \\
\hline Küçük RT'ler & Kişisel & 50W-20kW & $\begin{array}{c}\text { Çiftlik evleri, } \\
\text { Telekomünikasyon alıcısı, } \\
\text { Radyo Kulesi, Seralar, } \\
\text { Acil Telefonları vb. }\end{array}$ & Var & Yok & Düşük \\
\hline
\end{tabular}

Rüzgar türbinleri için bilinen ve daha çok uygulanılan elektrik üretiminin şehir dışı alanlarda yüksek güçlerde olup iletim ve dağıtım hatlarıyla şehirlerdeki kullanıcılara aktarılmasıdır. Rüzgar enerjisinden elektrik enerjisi üretiminin başka bir yolu ise şehirlerdeki binaların çatısına küçük ölçekli rüzgar türbinlerinin kullanılmasıdır. Bu tür çatı uygulamaları ile şehir içindeki rüzgar enerjisinden faydalanılabilmek ve rüzgar türbinlerinin yaygınlaşmasını sağlamak mümkündür. Ayrıca üretimin şehirlerde yaygın olarak yapılabilmesi ile bu iletim ve dağıtım hatlarının yapımından ve hatlarda oluşan kayıplardan tasarruf edilebilmekte ve üretim tüketimin olduğu yerde yapılabilmektedir. Böylelikle şehir dışında yüksek güçlü rüzgar türbini kurulumu için gerekli koşullar en aza indirgenebilmektedir. Rüzgar türbinlerinin çatılara ve özellikle yüksek yapıların çatılarına uygulanması ile rüzgar hızından da oldukça yüksek verim alınabilir ve böylelikle rüzgar türbini için gerekli kule masrafindan kısılabilmekte ve bu bakımdan da tasarruf edilebilmektedir.

Tüm bu avantajlarının yanında bu sistemlerin dezavantajları da mevcuttur; çatıya ilave ağırlık, gürültü, türbülanslı rüzgar dolayısıyla titreşim, ..gibi. Alınacak önlemler ise, mevcut yapıların çatılarına konulacak rüzgar türbinlerinin ağırlığı hesaplanılarak binanın dayanmasına dikkat edilmesi inşaat mühendisliğinin belirlemiş olduğu koşullar altında irdelenmelidir. Rüzgar türbinlerinin oluşturacağı gürültü, sessiz çalışan türbin tasarımı yapılarak giderilmelidir. Tüm bunların yanında rüzgar türbini seçimi şehir şartlarına ve şehirdeki rüzgar türbülansına uygun olmalıdır. Sistemde, şehir şartlarındaki rüzgar türbülansına dayanıklı türbinler tasarlanmalıdır. Şehir içi çatı uygulamalarında kullanılabilecek dikey eksenli rüzgar türbinleri için yeni tasarımlar günümüzün araştırma konuları olup, belirtilen bu sistemlerin ve problemlerinin iyi bilinmesi ile problemlere çözüm arayışı için araştırma geliştirme çalışmaları yapılmalıdır.

\section{DİKEY EKSENLİ TÜRBIINLER}

Dikey eksenli rüzgar türbin sistemlerinin dönüş ekseni rüzgarın yönüne diktir. Böylece bu türbinler rüzgarı her yönden alabilme ve buna göre dönüş hareketi yaparak elektrik üretebilmektedir. Bu sebepten dolayı yatay eksenli rüzgar türbinlerine kıyasla bir üstünlüğü bulunur. Verim olarak yatay eksenli türbinlerle kıyaslandığında daha düşük verimlidir, rüzgarı sürükleyerek kaldıran bu türbinlerin verimi ise yaklaşık olarak \%35'dir. Bu türbinler herhangi bir kuleye ihtiyaç duymadan düşük rüzgar hızlarında da çalışabilmektedir.

\section{A. Savonius Rüzgar Türbinleri}

Savonius rüzgar türbini Finlandiya'lı mühendis Sigurd J. Savonius tarafindan 1925 yılında keşfedilmiştir. Bu türbin, merkezleri simetrik olarak kaydırılmış kanatlar iki yarım silindirden oluşmakta olup iki yatay disk arasına yerleştirilmiştir. Herhangi bir yönde gelen rüzgarın etkisiyle, silindirin iç kısmında pozitif bir moment oluştururken dış kısmında negatif bir moment oluşturmaktadır. Oluşan bu momentlerden pozitif moment negatif momentten daha yüksek olduğundan dönme sağlanır ve bu dönme hareketi pozitif moment yönünde oluşmaktadır. Savonius rüzgar türbini, yapısının basit olması ve kolay inşa edilmesi ile birlikte başlangıç torklarının yüksek olması gibi önemli özelliklerinden dolayı ilgi çekmektedir. Bunun sebebi, aerodinamik yapıları gereği herhangi bir yönde esen rüzgarı alabilme özelliğinden kaynaklanmaktadır. Savonius rüzgar türbinlerinin bakımı ve işletmesi oldukça basittir [5]. 


\begin{tabular}{|c|c|c|}
\hline & $\begin{array}{l}\text { BŞEÜ Fen Bilimleri Dergisi } \\
6(2), 539-551,2019\end{array}$ & $\begin{array}{r}\text { BSEU Journal of Science } \\
\text { DOI: } 10.35193 / \text { bseufbd.643828 }\end{array}$ \\
\hline $\begin{array}{l}\text { BILECIKSEYHEDEBAL } \\
\text { ONIVERSITESI }\end{array}$ & & e-ISSN: 2458-7575 (http://dergipark.gov.tr/bseufbd) \\
\hline
\end{tabular}
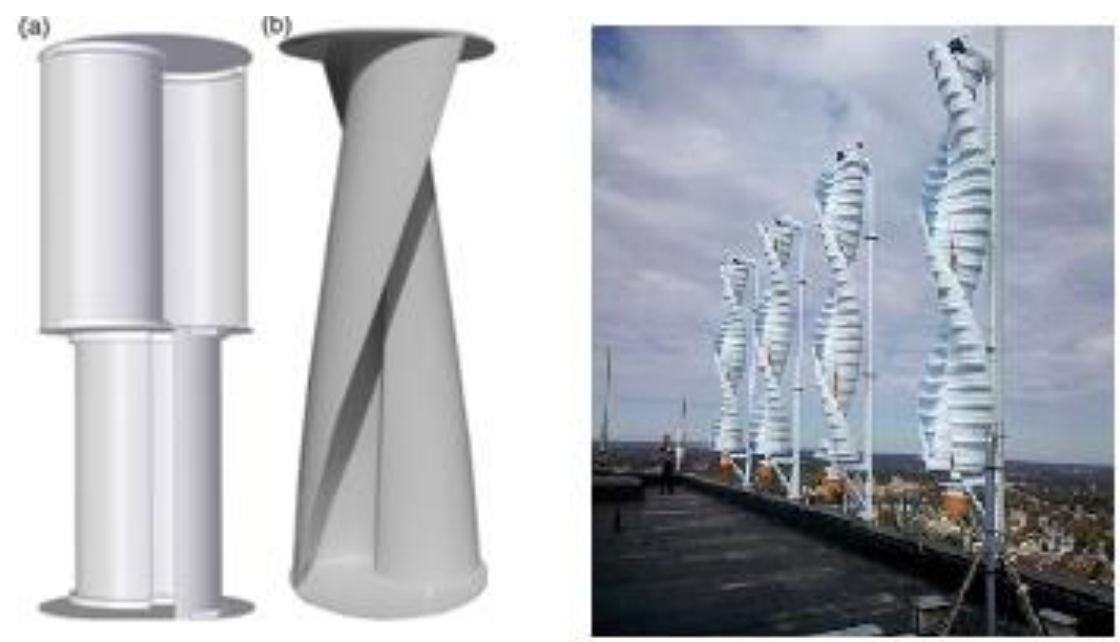

Şekil 3. Savonius Türbin [6]

Savonius tipi rüzgar türbinleri diğer dikey eksenli rüzgar türbinlerine kıyasla hem düşük rüzgar hızlarında iyi başlangıç karakteristiklerine sahip olması hem de herhangi bir yönde esen rüzgarı alabilmesinden dolayı ve bunun yanı sıra yapımının kolay ve ucuz olması, rüzgarın yönünden bağımsız olarak başlangı̧ torkunun yüksek olması gibi birçok avantaja sahiptir. Fakat aerodinamik performansı düşük olan Savonius RT'lerinin, ilk uygulama alanları; havalandırma, su pompalama gibi alanlarla kısıtlı kalmıştır. Savonius RT'nin birçok avantajı bünyesinde bulundurmasına rağmen, aerodinamik performanslarının düşüklüğünden dolayı rüzgar enerjisi alanında son yıllara kadar kullanılmamıştır. Günümüze gelindiğinde Savonius rüzgar türbini üzerinde yapılan çalışmalar aerodinamik performansın iyileştirilmesi ile birlikte rüzgar enerjisinde kullanılması hız kazanmaya başlamıştır.[7,8]

Yapılan çalışmalara bakıldığında ilk olarak Savonius rüzgar türbininin performansını değerlendirmek ve geliştirmek için Aldoss ve Najjar'ın yapmış oldukları çalışmada hem rüzgarın gerisinde hem de rüzgara doğru, çark kanatlarının bir optimum açı ile geriye doğru salınmasına müsaade ederek geliştirmişlerdir.[7] $\mathrm{Bu}$ çalışmanın yanı sıra Savonius rüzgar türbinin çalışma etkinliğini artırmak için Reupke ve Probert ise türbin kanatlarının kavisli kısımlarının yerine bir sıra menteşelenmiş kanaţ̧ıklar yerleştirmiştir. Yerleştirdikleri bu kanatçıklar rüzgara doğru ilerlerken, rüzgar basıncının etkisinde otomatik olarak açılmış ve daha az akış direnci elde edilmiştir. Kanatçıkların ilk konuma gelirken, tekrar otomatik olarak kapandığını tespit edip, çok düşük uç hız oranlarında, düzeltilmiş parçalı kanatlı çarklardan, klasik Savonius türbinlerine oranla daha yüksek momentler elde edildiğini gözlemlemişlerdir [9]. Rüzgâr türbinlerinin performans eğrileri hesaplanırken hız katsayısı ve güç katsayısına bakılmaktadır ve ona göre değerlendirme yapılmaktadır. Bu bağlamda savonius rüzgâr türbinlerinin performans eğrisi üzerinde Mahmoud'un yapmış olduğu deneysel çalışmalarında türbinin en boy oranı üzerine de incelemeler yapmışıı ve bu çalışmada en-boy oranının yükselmesiyle güç katsayısında bir artış olduğu sonucuna varmıştır. Bu sonuca dayanarak performansta artış gözlemlenmiştir. [10]. 


\begin{tabular}{|c|c|c|}
\hline & $\begin{array}{l}\text { BŞEÜ Fen Bilimleri Dergisi } \\
6(2), 539-551,2019\end{array}$ & $\begin{array}{r}\text { BSEU Journal of Science } \\
\text { DOI: } 10.35193 / \text { bseufbd.643828 }\end{array}$ \\
\hline $\begin{array}{l}\text { BIIECIISEYHEDEBALI } \\
\text { ONIVERSITESI }\end{array}$ & & e-ISSN: 2458-7575 (http://dergipark.gov.tr/bseufbd) \\
\hline
\end{tabular}

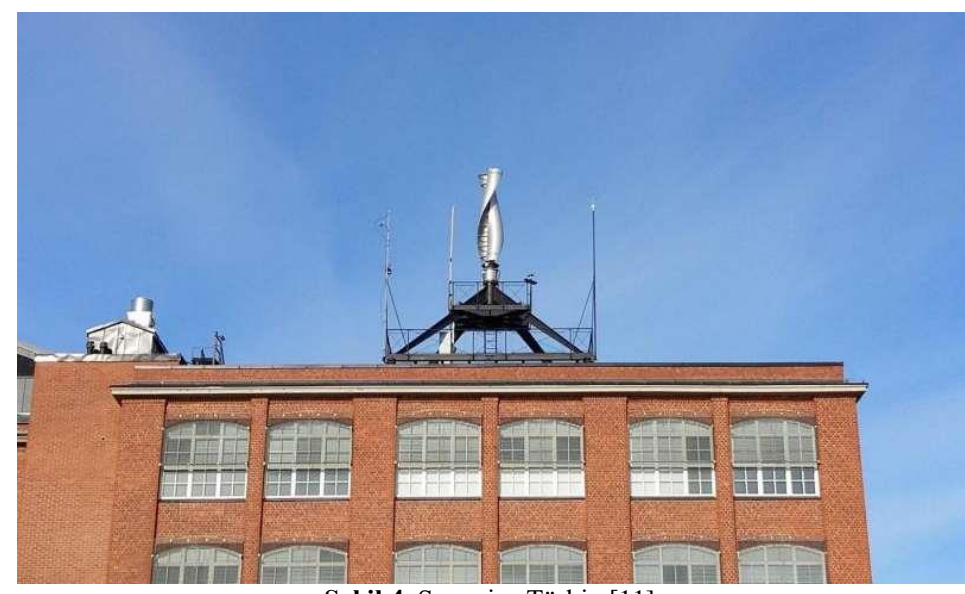

\section{B. Darrieus Rüzgar Türbinleri}

Şekil 4. Savonius Türbin [11]

Fransız mühendis George J.M. Darrieus tarafından 1931 yılında icat edilmiştir. Darrieus rüzgar türbininin yüksek performansa sahip olmasındaki en büyük etken kanatlarının düzgün bir aerodinamik yapıya sahip olmasıdır. Darrieus rüzgar türbininin kanatları üzerindeki çekme gerilimi hafif bir eğime sahiptir ve bu sebeple kanatlardaki çekme gerilimleri minumuma inmektedir. Bununla birlikte kanatları geometrik formlu aerodinamik profile sahip olduğundan yüksek performanslıdır. Bu türbin yüksek hızlarda çalışabilir ve türbin; 2 veya 3 kanatlı olur Fakat ilk hareket için bir tahrik motoru gereklidir.

Düşey eksenli Darrieus tipi rüzgâr türbininde, iki kanat düşey şekilde yerleştirilmiş ve bu kanatlar yaklaşık olarak türbin mili uzun eksenli olan bir elips oluşturacak biçimde yerleştirilmiştir. Kanatların içbükey ve dışbükey yüzeyleri arasındaki çekme kuvveti farkı nedeniyle dönme hareketi oluşur. Yapısı gereği Darrieus tipi rüzgâr türbinlerinde, devir başına iki kere en yüksek tork elde edilir.

\section{H-Darrieus Rüzgar Türbinleri}

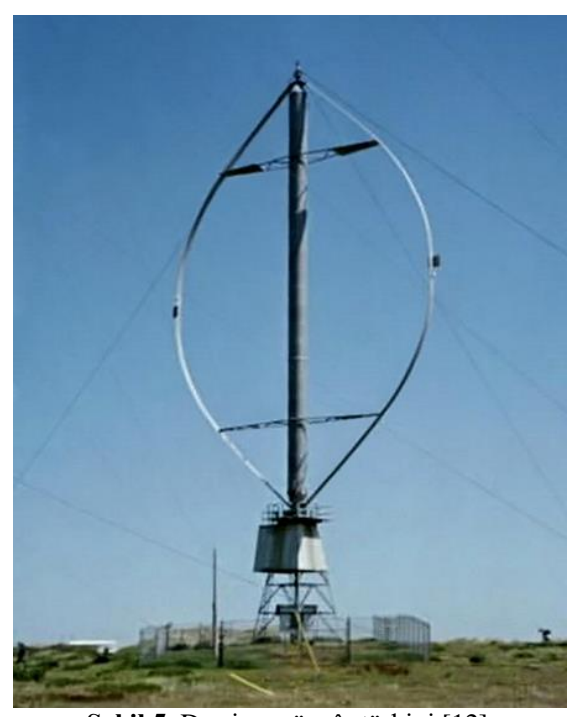

Şekil 5. Darrieus rüzgâr türbini [12]

Dikey eksenli Darrirus rüzgar türbininin geliştirilmesiyle meydana gelen daha bu türbin temel olarak Darrirus rüzgar türbindeki kavisli rotor bıçaklarının yerini düz bıçakların almasıyla meydana gelen H-Darrieus modelinde rüzgar türbinin en önemli iki farkı aerodinamik profilinin düzgün olması ve kanatlara pitch kontrol uygulanmasidır. 


\begin{tabular}{|c|c|c|}
\hline & $\begin{array}{l}\text { BŞEÜ Fen Bilimleri Dergisi } \\
6(2), 539-551,2019\end{array}$ & $\begin{array}{r}\text { BSEU Journal of Science } \\
\text { DOI: } 10.35193 / \text { bseufbd.643828 }\end{array}$ \\
\hline $\begin{array}{l}\text { BILCCIKEYYEDEBALI } \\
\text { OLIVERSITESI }\end{array}$ & & e-ISSN: 2458-7575 (http://dergipark.gov.tr/bseufbd) \\
\hline
\end{tabular}

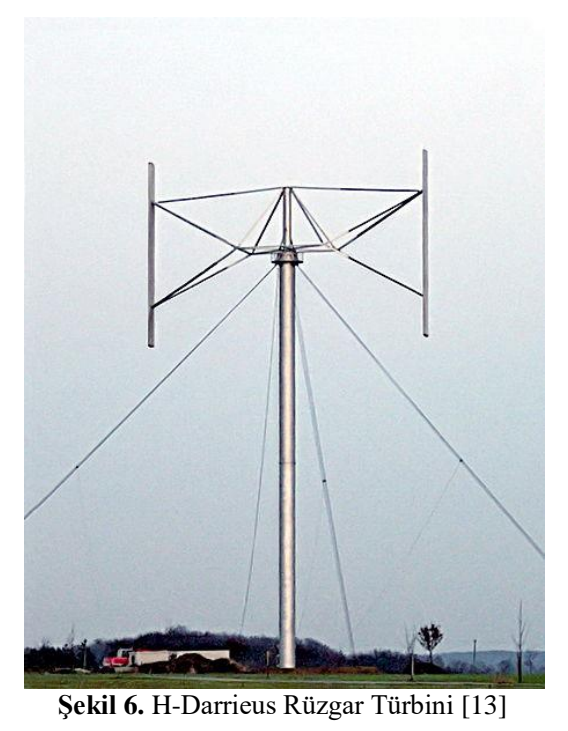

Yapılan çalışmalara bakıldığında Darrieus rüzgar türbininin kanatlarının kaldırma kuvveti ile dönmesi nedeniyle güç artış potansiyellerinin saptanması bu tip rüzgar türbinini ilgi çekici hale getirdiği görülmektedir. İlk defa Darrieus rüzgar türbinin güç üretimine etkisinin doğrulanmış hesaplamalı akışkanlar mekaniği (HAD) analizleri vasıtasıyla inceleyen Kline-Fogleman çalışmasında analizleri karşılaştırarak olumlu ve olumsuz etkilerininin olduğunu belirlemiştir. Bunun sonucunda Darrieus türbinleri rüzgarı her yönden alabilme kabiliyeti ve türbinin alt kısmına jeneratörün konulabilmesi gibi avantajları ve bunun yanı sıra kurulumunda ki maliyet düşüklüğü ile birlikte kullanım alanının genişletilmesi üzerinde çalışmalar devam etmektedir [14-15]. Özellikle küçük ölçekli güç üretiminde Darrieus tipi rüzgar türbinlerinin performansı Sandria'nın hazırladığı raporlar sayılmazsa son yıllara kadar detaylı bir şekilde incelenmemiştir [16,17]. Günümüze gelindiğinde bu konu üzerinde birçok araştırma yapıldığı görülmektedir. Tescione ve ark. [18], H-tipi bir Darrieus türbininin art-izini parçacık görüntülemeli hız ölçümü (PGHÖ/PIV) tekniğiyle detaylı inceleyerek bu konunun öncülerinden biri olmuştur. Çalışmanın ana bulguları şunlardır: 1) türbin art-izinin asimetrik olması, 2) yüksek türbülans sayesinde yayılımın artmasıyla art-izinin YERT'lere kıyasla daha erken toparlanması ve 3) ters yönde dönen girdapların etkileşim içine girmesiyle üç çap ark mesafeden sonra tekil girdap yapılarının ve kanat art-izlerinin ortadan kaybolması, sadece kenarlarda ters yönde dönen girdap yapılarının kalması. Lam ve Peng [19], Tescione ve arkadaşlarının incelemiş olduğu aynı problemi sayısal analiz kullanarak iki ve üç boyutlu hesaplamalı akışkanlar dinamiği (HAD) yardımıyla incelemişlerdir ve yapmış oldukları deneylerle kullandıkları sayısal analiz programı HAD arasında uyum gözlemlemişlerdir. Bu sayede, ileriki çalışmaların HAD yardımıyla belli bir güven aralığı içerisinde yapılabilmesinin önü açılmıştır. Li ve ark. [20], yaptıkları deneysel çalışmada, NACA 0021 kanat kullanan iki kanatlı H-tipi Darrieus türbininin güç ve art-izi karakteristiklerini, ilk defa uç hızı oranına bağlı olarak, incelemiş̧lerdir. DERT'ler için çeşitli başarım iyileştirme çalışmaları da gerçekleştirilmişstir. Bunlar, genellikle rotor dışına stator yada muhafaza yerleştirilmesi ve böylece akışın istenen şekilde yönlendirilmesi şeklindedir [21]. Ayrıca, art-izinin DERT'lerde daha çabuk azalması sebebiyle tarla diziliminde yeni firsatlar ortaya çıkmaktadır. Buna göre DERT'ler YERT'lere göre daha yakın yerleştirilebilir ve hatta etkileşim sayesinde tekli DERT'lere kıyasla güç artışı gözlemlenebilir [22, 23]. Performansını arttırmak için $H$ tipi Darrieus rotorunun etrafına veya üstüne ilave cihazlar yerleştirmek için bazı araştırmalar yapıldı. Bu cihazlar rüzgar toplama cihazı (WGD) olarak adlandırılır. Rüzgar toplama cihazlarının eklenmesi ile ilgili araştırmalar için, araştırmacıların çoğu, rotorun etrafında rüzgar yönü ile birlikte farklı türde kanatlar kurmuşlardır [24]. Başka bir yol, ise rüzgar toplama cihazını rotorun altına ve üstüne ayarlamaktır. Bu tip bir rüzgar toplama cihazı, NEAU Çin'den Prof. Li tarafından önerilmiştir [25].

Performans arttırmak için kanat üzerine yapılan çalışmalara bakacak olursak; Koca ve ark. [26] ile Genç ve ark. [27] NACA 4412 rüzgar türbini kanat profili üzerinde oluşan akış yapılarını gözlemleyebilmek için farklı Reynolds sayılarında ve hücum açılarında çeşitli deneyler yapmışlardır. Deneyler, kanat profili üzerinde oluşan laminer ayrılma kabarcığının Reynolds sayısının ve hücum açısının değişimine bağlı olarak konumunun ve boyutun değiştiğini göstermiştir. Çok düşük hücum açılarında frekansları yüksek girdap dökülmesine sahip kısa 
kabarcık görülürken hücum açısının artmasına bağlı olarak frekansı düşük girdap dökülmelerine sahip uzun kabarcık oluşumları meydana gelmiştir. Aynı aerodinamik araştırmacılar [28, 29] NACA 4412 kanat profili üzerindeki akış durumlarını belirledikten sonra laminer ayrılma kabarcı̆̆ 1 ve akış ayrılmalarını önlemek için seçilen kanat profili üzerine pasif kontrol elemanı olacak şekilde zımpara kağıdı yerleştirmişlerdir. Zımpara kağıdı yerleştirilmiş NACA 4412 kanat profili için değişik hücum açılarında ve Reynolds sayılarında deneysel inceleme yapılmıştır. Deney sonuçları şu durumları göstermiştir: (i) kanat profiline zımpara kağıdı kullanıldığında akış ayrılmasının ana kaynağı olan ters basınç gradyenlerine karşı konulmuş ve akış ayrılması önlenmiştir, (ii) laminer ayrılma kabarcığı oluşumu olumlu yönde etkilenmiş (ya konumu değiştirilmiş ya da boyutu küçültülmüş) ve bu durumun da kuvvet katsayısı grafiğinde gösterilen kaldırma katsayısının $\left(C_{L}\right)$ artmasını sağlamıştır.

Rotorun yukarısında ve aşağısında kesilmiş bir koni biçimli yapı olarak tasarlanan bu cihazın temel avantajı, rüzgar hızını tüm rüzgar yönlerinden artırabilmesidir. Rüzgâr yönü boyunca yer kaplaması gerekmeyecek, böylece tüm rotor yapısı, büyük itme ve çekme kuvvetinden etkilenmeyecektir. Ek olarak rüzgar toplama cihazı rotor bıçaklarında yağmur, kar ve buzu önlemede belli bir rol oynamaktadır. Sayısal simülasyon ve rüzgar tüneli testlerinin sonuçlarına göre, bu cihaz ile rotorun güç katsayıları, cihaz olmayan rotordan çok daha yüksektir.

\section{Savonius Darrieus ve H-Darrieus Rüzgar Türbinleri}

Rüzgar türbinlerinde yaygın olarak kullanılan iki tip rotor vardır. Savonius rotorları başlangıç için düşük bir tork gerektirir, ancak verimleri düşüktür. Darrieus rotorlarının verimliliği yüksektir, ancak çalıştırılmaları zordur. Düşük başlangıç şartına sahip, yüksek aerodinamik performans hedefleyen bir DarrieusSavonius kombine rotor, birçok araştırmacının dikkatini çekmiştir. Darrieus ve Savonius rüzgar türbinlerinin bütünleşik tasarımına ihtiyaç duyulmasında ki ana sebep Darrieus rüzgar türbininin ilk hareket için bir tahrik motoruna ihtiyaç duymasıdır. Darrieus rüzgar türbini Savonius rüzgar türbinini bir tahrik motoru olarak kullanır. $\mathrm{Bu}$ sebeple Darrieus ve Savonius rüzgar türbinlerinin bütünleşik kullanımı performansı arttırmayı hedeflemektedir. Yapılan bütünleşik tasarımlarda başlangıç performansı iyileştirilmiştir fakat diğer bir taraftan sisteme Savonius rotor eklendiğinde yüksek dönme hızındaki güç performansı büyük ölçüde etkilenir. Bunun nedeni esas olarak Savonius rotorunun uç hız oranı üniteden büyük olduğunda yüke dönmesidir. Bu nedenle, kombinasyon faktörleri, rotor çapı, birleştirme açısı, en boy oranı vb. gibi nicelikler derinlemesine araştırılmalıdır.

Yapılan çalışmalara bakıldığında maksimum güç katsayısınının etkili bir sonucuna ulaşmak adına Tetsuya ve ark. çalışmalarında iki tip hibrit konfigürasyon tasarlayarak hangisinde daha etkili sonuç gözlemlediklerini sunmuşlardır. Bu çalışmada tek başına rüzgar türbini jeneratörü sistemleri için Darrieus lift tipi ve Savonius drag tipi rotorların uygun hibrid konfigürasyonu dinamik simülasyon modeli kullanılarak tartışılmıştır. A Tipi konfigürasyonunda Savonius rotoru Darrieus rotorunun içine, B Tipi konfigürasyonunda Savonius rotoru Darrieus rotorunun dışına yerleştirilmiştir. Çıkış özelliklerinin hesaplanan sonuçları ve maksimum güç katsayısı noktalarında çalıştırılan sistemin dinamik davranışı, rüzgar hızına göre hassas çalışma davranışına sahip olan ve daha kısa bir dönme ekseni nedeniyle kompakt olarak tasarlanabilen A tipi konfigürasyonun daha etkili olduğu gözlemlenilmiştir [32].

Diğer bir çalışmada Savonius rotorun yanı sıra Savonius-Darrieus makinesinin performansını incelemek için deneysel araştırmalar yapan R. Gupta ve ark. biri Savonius rotoru, diğeri Savonius-Darrieus makinesi olmak üzere iki tip model tasarlayıp üretimini gerçekleştirdiler. Savonius rotoru, $8 \mathrm{~cm}$ kepçe çapına ve $20 \mathrm{~cm}$ yüksekliğe sahip, örtüşme varyasyonu sağlayan iki kanatlı bir sistem olarak tasarlandı. Savonius-Darrieus makinesi için, üst kısımda, kepçe çapı $8 \mathrm{~cm}$ ve yüksekliği $10 \mathrm{~cm}$ olan iki kanatlı bir Savonius rotoru olup ve alt kısımda, $10 \mathrm{~cm}$ yüksekliğinde ve $4 \mathrm{~cm}$ yarıçaplı üç kavisli bıçağa sahip Darrieus makinesi yerleştirildi. Üsst üste binme varyasyonu üst kısımda yapıldı. Bunlar bir rüzgar tünelinde test edilerek aynı test koşulları altında sadece Savonius rotoruna kıyasla Savonius-Darrieus makinesi için güç etkinliğinde bir gelişme olduğu gözlemlenmiştir. [33]. 


\begin{tabular}{|c|c|c|}
\hline & $\begin{array}{l}\text { BŞEÜ Fen Bilimleri Dergisi } \\
6(2), 539-551,2019\end{array}$ & $\begin{array}{r}\text { BSEU Journal of Science } \\
\text { DOI: } 10.35193 / \text { bseufbd.643828 }\end{array}$ \\
\hline $\begin{array}{l}\text { BiLECEIKEYY EDEBALI } \\
\text { UNIVERSITESI }\end{array}$ & & e-ISSN: 2458-7575 (http://dergipark.gov.tr/bseufbd) \\
\hline
\end{tabular}

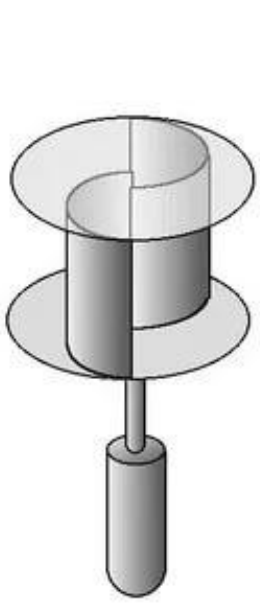

Savonius-Rotor

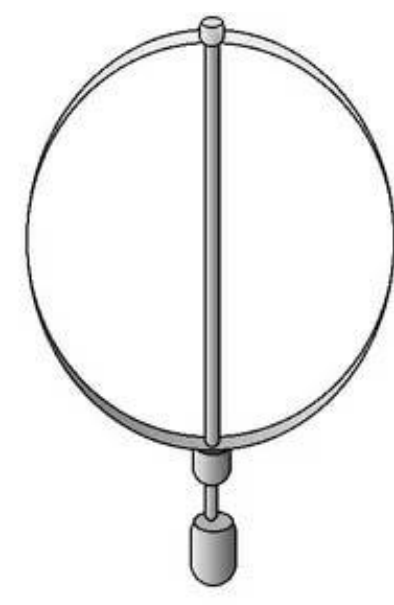

Darrieus-Rotor

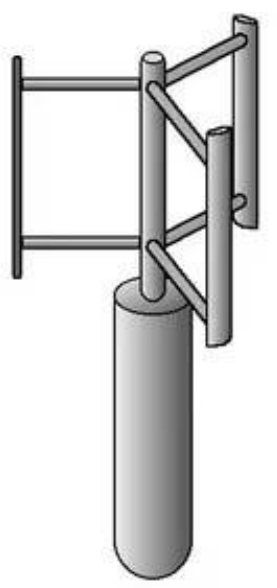

H-Rotor

Şekil 7. Türbin Modelleri [30]

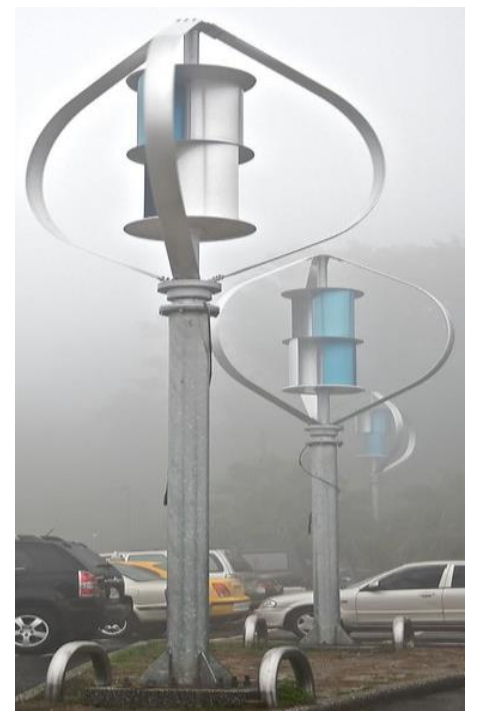

Şekil 8. Savonius ve Darrieus bütünleşik tasarımı [31]

Düşük başlangıç şartına sahip, yüksek aerodinamik performans hedefleyen bir Darrieus-Savonius kombine rotor tasarımı için rotorlar arasındaki yarıçap oranı ve bağlantı açısı önemli faktörlerdir. Xiaoting Liang ve ark. bu iki parametrenin verimlilik ve başlangıç performansı üzerindeki etkileri hesaplamalı akışkanlar dinamiği yaklaşımı ile incelenmişlerdir. Statik torku elde etmek için Reynolds ortalamalı Navier-Stokes denklemlerini gerçekleştirilebilir k- $\varepsilon$ türbülans modeliyle çözen sürekli simülasyonlar yapılmıştır. Kombine rotorun güç katsayısını farklı uç-hız oranlarında hesaplamak için simülasyonlar yapıldı. Bir dizi konfigürasyon test edilerek ve birleştirilmiş rotor için optimum bağlantı açısı ve yarıçap oranı, 0.363'lük bir maksimum güç katsayısı ve $2 \mathrm{~m} / \mathrm{s}$ 'lik bir rüzgar hızında 0.1 Nm'nin altındaki başlangıç torku elde edilmiştir [34].

Darrieus rüzgar türbinleri, düşey eksenli rüzgar türbinlerinin içinde aerodinamik açısında en verimli olarak kabul edilir ancak bu türbinler zayıf başlangıç torkuna sahip olduğundan ve bu nedenle zayıf rüzgar hızlarında kendiliğinden çalışmaya başlayamadıklarından, Ali Shan Siddiqui ve ark. çalışmalarında kombine Savonius Darrieus rüzgar türbinleri, türbin tork karakteristiklerini iyileştirmek ve kendi kendine çalışmaya başlamalarını sağlamak için çözüm olarak belirleyip Darrieus ve Savonius rüzgar türbininin üç olası 
düzenlemesini test etmek için deneyler yapmışlardır. Bu deneylerde her bir modelin performansını değerlendirmek için benzer çalışma koşullarında model 1, 2 ve 3 olarak adlandırdıkları tasarımları test etmişlerdir. Model 1; Savonius rotorunun Darrieus rüzgar türbininin ortasına yerleştirilmiş olup model 2 ve 3 'te ise; Darrieus rotorunun tepesine bağlanan Savonius rotoru ve Darrieus türbininin altına bağlanan Savonius rotoru arasındaki modellemeler arasında model 1'in en yüksek performansa sahip olduğu sonucuna ulaşılmıştır [35].

Yapılan çalışmalara bakıldığında küçük ölçekli rüzgar türbinleri ve özellikle dikey eksenli türbinler üzerine çalışma az sayıdadır. Dikey eksenli türbinlerin şehir içi uygulamaları için uygulanabilirliği düşünüldüğünde bu türbinler üzerine daha fazla çalışma yapılması gerekmekte olup ayrıca yeni tasarım araştırma ve geliştirme çalışmaları yapılmalıdır.

\section{SONUÇ}

Yenilenebilir enerji kaynakları içerisinde olan rüzgar enerjisi, artan çevre kirliliği ile beraber son yıllarda önem kazanmaya başlamıştır. Özellikle 1973 yılında yaşanan petrol krizi ile beraber yeni enerji kaynakları arayışı ile yenilenebilir enerji kaynaklarının kullanılması daha fazla artış göstermiştir [36]. Rüzgar, güneş enerjisinin dünyayı ısıtmasıyla atmosferde soğuk hava kütlesine sahip yüksek basınç alanları ve sıcak hava kütlesine sahip alçak basınç alanları oluşmaktadır. Atmosferde hava kütleleri yüksek basınç alanından alçak basınç alanlarına doğru hareket ederler. Hava kütleleri arasındaki ısı ve basınç farklılıklarından oluşan hava akışı rüzgar olarak adlandırılır.

Rüzgar türbinlerinden elektrik enerjisi elde edilmesi, rüzgarda bulunan kinetik enerji pervaneler vasıtasıyla rotorda mekanik enerjiye çevrilir. Daha sonra dişli kutusu yardımıyla bu enerji jeneratörlere aktarılır ve jeneratörden elektrik enerjisi elde edilmiş olur. Rüzgar türbinlerinin işletme ve bakım maliyetleri yapılan çalışmalarla günden güne düşüş göstermektedir. Yatay eksenli rüzgar türbinleri için gerekenler; kurulum için gerekli olan geniş alan, alınması gereken izinler, uygun alan belirlenmesi, yüksek kurulum maliyeti ve yüksek rüzgâr hızının gerekliliğinden dolayı artış oranı beklenen tahminlerin altında kalmıştır [37].

Günümüzde rüzgardan gelen enerjiyi daha fazla kullanabilmek adına düşey eksenli rüzgar türbinlerinin ön plana çıktığı görülmektedir. Bunun sebebi küçük ölçekli rüzgar türbinlerinin yaygınlaşmasının insanların enerji ihtiyacını karşılamakta önemli rol oynamasının yanı sıra maliyet düşüklüğü, kurulum için geniş alan ihtiyacı ve alınacak izinler gibi sıkıntılarının bulunmaması bu konuyu araştırmacılar tarafından cazip hale getirmiştir. Düşey eksenli rüzgar türbinlerinin yapılan çalışmalarda performansını arttırmak için SavoniusDarrieus rüzgar türbini bütünleşik tasarımından faydalandıkları görülmektedir. Bu sebeple yapılan çalışmalara göre tek başına kullanılan Savonius veya Darrieus rüzgar türbinlerine kıyasla bütünleşik kullanımının daha etkili performans sonucunu verdiği araştırmalarla kanıtlanmıştır. Dikey eksenli türbinlerin şehiriçi uygulamaları için uygulanabilirliği düşünüldüğünde bu türbinler üzerine daha fazla çalışma yapılması gerekmekte olup ayrıca yeni tasarım araştırma ve geliştirme çalışmaları yapılmalıdır.

\section{KAYNAKLAR}

[1] Türkiye İstatistik Rüzgar Enerjisi İstatistik Raporu (2019). http://www.tureb.com.tr/files/bilgi_bankasi/ turkiye_res_durumu/istatistik_raporu_temmuz_2019.pdf

[2] Mustafa Çalışkan, Türkiye Rüzgar Enerjisi Potansiyeli Raporu 2010. https://www.mgm.gov.tr/files/ haberler/2010/rets-seminer/2_mustafa_caliskan_ritm.pdf

[3] Koç, E., \& Şenel, M. C. (2013). Dünyada ve Türkiye'de enerji durumu-genel değerlendirme. Mühendis ve Makina, 54(639), 32-44.

[4] Nurbay, N., \& Çınar, A. (2005). Rüzgar türbinlerinin çeşitleri ve birbirleriyle karşılaştırılmasıs. III. Yenilenebilir Enerji Kaynaklart Sempozyumu, 19-21.

[5] Mojola, O. O. (1985). On the aerodynamic design of the Savonius windmill rotor. Journal of Wind Engineering and Industrial Aerodynamics, 21(2), 223-231.

[6] Ricci, R., Vitali, D., \& Montelpare, S. (2014). An innovative wind-solar hybrid street light: development and early testing of a prototype. International Journal of Low-Carbon Technologies, 10(4), 420-429. 
[7] NEWMAN, B. (1974). Measurements on Savonius Rotor with Variable Gap, Proceedings of the University of Sherbrook Conference on Wind Energy. Sherbrooke, Quebec, 116s, Canada.

[8] Modi, V. J., \& Fernando, M. S. U. K. (1989). On the performance of the Savonius wind türbine, J. Sol. Energy Eng., 111(1): 71-81.

[9] Reupke, P., \& Probert, S. D. (1991). Slatted-blade Savonius wind-rotors. Applied Energy, 40(1), 65-75.

[10] Mahmoud, N. H., El-Haroun, A. A., Wahba, E., \& Nasef, M. H. (2012). An experimental study on improvement of Savonius rotor performance. Alexandria Engineering Journal, 51(1), 19-25.

[11] Svetlana Marmutova, M. (2016). The improved Savonius wind turbine captures wind in the cities: University of Vaasa, Doktora Tezi.

[12] ELİBÜYÜK, U., \& ÜÇGÜL, İ. (2014). Rüzgâr Türbinleri, Çeşitleri Ve Rüzgâr Enerjisi Depolama Yöntemleri. SDÜ Yekarum e-Dergi, 2(3).

[13] Giromill-Darrieus Rüzgar Türbinleri (2018). http://www.reuk.co.uk/Giromill-Darrieus-WindTurbines.html

[14] Howell, R., Qin, N., Edwards, J., \& Durrani, N. (2010). Wind tunnel and numerical study of a small vertical axis wind turbine. Renewable Energy, 35(2), 412-422.

[15] Goude, A.2012. Fluid Mechanics of Vertical Axis Turbines: Simulations and Model Development. Digital Comprehensive Summaries of Uppsala Dissertations from the Faculty of Science and Technology 998, Uppsala University.

[16] Banas J F, Sullivan W N.Sandia. 1976. Vertical-Axis Wind Turbine Program Technical Quarterly Report. Sandia Laboratuvarları

[17] Sheldalh R E, Klimas P C, Feltz L V. 1980. Aerodynamic Performance of a 5-Metre-Diameter Darrieus Turbine With Extruded Aluminum NACA-0015 Blades. Sandia Laboratuvarları.

[18] Tescione, G., Ragni, D., He, C., Ferreira, C. S., \& Van Bussel, G. J. W. (2014). Near wake flow analysis of a vertical axis wind turbine by stereoscopic particle image velocimetry. Renewable Energy, 70, 47-61.

[19] Lam, H. F., \& Peng, H. Y. (2016). Study of wake characteristics of a vertical axis wind turbine by twoand three-dimensional computational fluid dynamics simulations. Renewable Energy, 90, 386-398.

[20] Li, Q. A., Maeda, T., Kamada, Y., Murata, J., Yamamoto, M., Ogasawara, T., ... \& Kogaki, T. (2016). Study on power performance for straight-bladed vertical axis wind turbine by field and wind tunnel test. Renewable Energy, 90, 291-300.

[21] Shigemitsu, T., Fukutomi, J., \& Toyohara, M. (2016). Performance and flow condition of cross-flow wind turbine with a symmetrical casing having side boards. International Journal of Fluid Machinery and Systems, 9(2), 169-174.

[22] Araya, D. B., Craig, A. E., Kinzel, M., \& Dabiri, J. O. (2014). Low-order modeling of wind farm aerodynamics using leaky Rankine bodies. Journal of Renewable and Sustainable Energy, 6(6), 063118.

[23] Dabiri, J. O., Greer, J. R., Koseff, J. R., Moin, P., \& Peng, J. (2015, March). A new approach to wind energy: opportunities and challenges. In AIP Conference Proceedings (Vol. 1652, No. 1, pp. 51-57). AIP.

[24] Chong, W. T., Fazlizan, A., Poh, S. C., Pan, K. C., Hew, W. P., \& Hsiao, F. B. (2013). The design, simulation and testing of an urban vertical axis wind turbine with the omni-direction-guide-vane. Applied Energy, 112, 601-609. 
[25] Li, Y., Zhao, S., Tagawa, K., \& Feng, F. (2018). Starting performance effect of a truncated-cone-shaped wind gathering device on small-scale straight-bladed vertical axis wind turbine. Energy Conversion and Management, 167, 70-80.

[26] Koca, K., Genç, M. S., Açıkel, H. H., Çağdaş, M., \& Bodur, T. M. (2018). Identification of flow phenomena over NACA 4412 wind turbine airfoil at low Reynolds numbers and role of laminar separation bubble on flow evolution. Energy, 144, 750-764.

[27] Genç, M. S., Koca, K., Açıkel, H. H., Özkan, G., Kırış, M. S., \& Yıldız, R. (2016). Flow characteristics over NACA4412 airfoil at low Reynolds number. EPJ Web of Conferences, 114, 02029 (2016).

[28] Genç, M. S., Koca, K., \& Acikel, H. H. (2019). Investigation of pre-stall flow control on wind turbine blade airfoil using roughness element. Energy, 176, 320-334.

[29] Koca, K., Genç, M. S., \& Açıkel, H. H. Rüzgar Türbini Kanadı Üzerindeki Yüzey Pürüzlülüğü Etkisinin Deneysel İncelenmesi. Çukurova Üniversitesi Mühendislik-Mimarlık Fakültesi Dergisi, 31(ÖS2), 127134.

[30] Volker Quaschning: Regenerative Energiesysteme. (2007). Hanser Verlag, München.

[31] Combined Darrieus-Savonius generator used in Taiwan Jul 18, 2016 12:14 AM. URL: https://en.wikipedia.org/wiki/Savonius_wind_turbine

[32] Wakui, T., Tanzawa, Y., Hashizume, T., \& Nagao, T. (2005). Hybrid configuration of Darrieus and Savonius rotors for stand-alone wind turbine-generator systems. Electrical Engineering in Japan, 150(4), 13-22.

[33] R. Gupta, R. Das \& K.K. (2006). Sharma: Proceedings of the International Conference on Renewable Energy for Developing Countries.

[34] Liang, X., Fu, S., Ou, B., Wu, C., Chao, C. Y., \& Pi, K. (2017). A computational study of the effects of the radius ratio and attachment angle on the performance of a Darrieus-Savonius combined wind turbine. Renewable energy, 113, 329-334.

[35] Ali Shan Siddiqui, Syet Nadeem Mian, Muhammad Alam, Muhammad Saleem ul Haq, Abdul Hameed Memon, Muhammad Shahzad Jamil Energy Nov. 2018. Experimental Study to Assess the Performance of Combined Savonius Darrieus Vertical Axis Wind Turbine at Different Arrangements. Publisher: IEEE DOI: 10.1109/INMIC.2018.8595538.

[36] Oğulata, R. T. (2003). Energy sector and wind energy potential in Turkey. Renewable and Sustainable Energy Reviews, 7(6), 469-484.

[37] Tabatabaeikia, S., Ghazali, N. N. B. N., Chong, W. T., Shahizare, B., Izadyar, N., Esmaeilzadeh, A., \& Fazlizan, A. (2016). Computational and experimental optimization of the exhaust air energy recovery wind turbine generator. Energy Conversion and Management, 126, 862-874. 